Ferris, whose multi-great-grandmother won Britain's last Olympic diving medal, they will demand the abolition of chromosomal gender verification, whereby the presence of a Barr body leads to disqualification, given the anomaly that powerful competitors with Turner's (XO) and the androgen insensitivity (or testicular feminisation, $\mathrm{XY}$ ) syndromes gain unfair advantage over men, while feeble Klinefelter's and wimpish adrenogenital syndromers and true hermaphrodites are excluded.

The new men's sports of association football, rugby, Australian rules, and Gaelic football will slowly get off the ground, with as much as $5 \%$ of the daily newspaper sports coverage. The England Men's squash team, as a special favour, will be allowed to play in the Midland Women's Squash League, although having to start in division twenty four. The Sports Council will issue strategic studies reports on "Men and Sport", to assist the regional offices in identifying, monitoring, and assessing specific initiatives designed to encourage men to participate in sport, with the formation of "Men and Sport" working parties to try to break down the barriers cause by the possible conflict that the roles of being "masculine" and being a "sportsman" provoke.

Sporting sociologist Johnny Hargreaves, multi-great-grandson of Jenny, his famous predecessor, will write "Sporting Males", the definitive account of critical issues in the history and sociology of men's sports, of which it will be said: "Most modern histories and sociologies of sports focus on those of women, but this book places men at the centre, and thus fills an important gap in the market. It views sport as part of a battle for control of the body, and, as such, as an important area for Masculinist intervention".

Then, to the plaudits of most Masculinists, but without the unqualified approval of $\mathrm{Lu}$ ciano Paglia (who, like his famous multi-greatgrandmother, will see Masculinism as being too seduced by the false prophet Rousseau, rather than following the true voice of Sade), men will seriously take to power dressing, the boardroom, neo-rock music, and formula one grand prix driving, and will begin to steadily narrow the performance gap in the athletic track events, the Marathon, the Olympic swimming distances, speed skating, and sprint and road cycling. They will gradually lose their expertise on the balance beam in gymnastics, but will become better on rings.

And contemporary Nobel Laureate for literature, Roberta Burns, will write re "Auld Nature" that:

'Her prentice han', she tried on woman, An' then she made the laddies $O$.'

\title{
High altitude research on Kangchenjunga, 1998
}

\author{
A J Pollard
}

In the post-monsoon climbing season in 1994, Charlie Hornsby and Roddy Kirkwood, two British GPs, reached the summit of Mount Everest $(8848 \mathrm{~m})$, the world's highest mountain, in ferocious winds. They were members of the 1994 British Mount Everest Medical Expedition, led by another GP, Dr Simon Currin, and other climbers reached the summit on Pumori and various "trekking" peaks in the Everest area. One expedition member, Dr Scott Parazynski, failed to make the trip but photographed the summit from NASA's Atlantis space shuttle instead during its 1994 flight! This was a research expedition in which a scientific team of more than 30 doctors, physiologists, and environmental scientists, led by $\mathrm{Dr}$ David Collier, undertook 19 research projects. These projects have since been presented at scientific meetings from Kathmandhu to Cusco and from Oxford to Lake Louise. After the success of the 1994 expedition "Medical Expeditions" developed-a charitable company which runs educational courses and high altitude physiological and environmental stud-

ies. In Autumn 1998, a further scientific expedition, to Kangchenjunga (the world's third highest mountain) in Eastern Nepal, is planned. The research team will be accompanied by a cohort of 50 subjects (in groups of 10) and a mountaineering team with climbing objectives in the area. Applicants interested in conducting projects during the expedition should send an application consisting of a referenced abstract of not more than 400 words and curriculum vitae to the address below. Information about "Mountain and high altitude medicine" (18-20 April 1997, North Wales), a practical three day course covering all aspects of medicine in remote places and the special problems of high altitude, organised by "Medical Expeditions", is available by telephoning Suzanne on 01438812671 or from the address below: Dr AJ Pollard, 12 Purcell Road, Marston, Oxford OX3 0HB. E mail: a.pollard@ic.ac.uk

"Medical Expeditions" is a charitable company limited by guarantee, registered in Scotland. (Company Number 140415. Charitable Number SC020922.) 